\title{
Pulmonary artery augmentation and aortic valve repair using novel tissue-engineered grafts
}

Hisayuki Hongu, MD, PhD, ${ }^{a}$ Masaaki Yamagishi, $\mathrm{MD}, \mathrm{PhD},{ }^{\mathrm{a}}$ Keiichi Kanda, $\mathrm{MD}, \mathrm{PhD},{ }^{\mathrm{b}}$

Yoshinobu Maeda, MD, ${ }^{\mathrm{a}}$ Tomoya Inoue, MD, PhD, ${ }^{\mathrm{b}}$ Hiroki Nakatsuji, MD, PhD, ${ }^{\mathrm{a}}$ and

Hitoshi Yaku, MD, $\mathrm{PhD}^{\mathrm{b}}$

\section{ABSTRACT}

Objectives: The objectives of this study were to evaluate the results when tissueengineered vascular grafts (TEVGs) are used as alternatives to autologous pericardium for surgically augmenting the pulmonary artery (PA) or aortic valve.

Methods: TEVG molds were embedded into subcutaneous spaces for more than 4 weeks preoperatively. Since 2014, 6 patients have undergone PA reconstruction, whereas 1 has undergone aortic valve plasty (AVP) with TEVGs. The time from mold implantation to the operation was 8.9 (range, 6.0-26.4) months. The age and body weight at the time of operation were 2.7 (range, 1.8-9.2) and 11.6 (range, 7.9-24.4) kg, respectively. Concomitant procedures comprised the Rastelli, palliative Rastelli, and Fontan operations in 2, 2, and 1 patient, respectively.

Results: The median follow-up period was 14.4 (range, 3-39.6) months. There were no early or late mortalities. Moreover, there were no TEVG-related complications, including aneurysmal changes, degeneration, and infection. In 5 patients who underwent PA augmentation, the postoperative PA configuration was satisfactorily dilated. The reconstructed aortic valve function was good in the patient who underwent AVP. Decreased leaflet flexibility due to leaflet thickening was not observed. One patient had postoperative PA re-stenosis; therefore, re-PA augmentation with TEVGs was performed. On histological examination, TEVGs consisted of collagen fibers and few fibroblasts, and elastic fiber formation and/or smooth muscle cells were not observed.

Conclusions: The midterm results of PA reconstruction and AVP with TEVGs were satisfactory. TEVGs might be a useful alternative to autologous pericardium in pediatric cardiovascular surgeries that often require multistage operations. (JTCVS Techniques 2022;12:143-52)

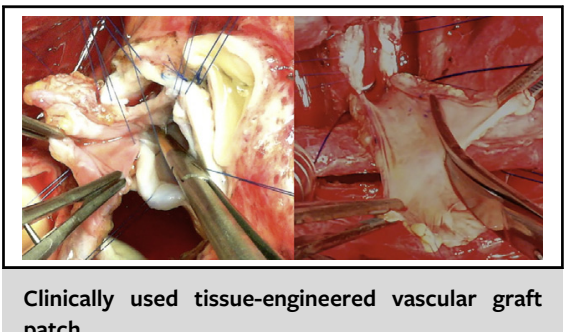
patch.

\section{CENTRAL MESSAGE}

Midterm outcomes of pulmonary artery reconstruction and aortic valve plasty with tissueengineered vascular grafts were satisfactory. Thrombosis, aneurysmal change, degeneration, and infection were absent.

\section{PERSPECTIVE}

Our tissue-engineered vascular grafts might be useful alternatives to autologous pericardium in pediatric cardiovascular surgeries, such as pulmonary artery augmentation, valve leaflet augmentation, and surgeries requiring multiple stages.
From the a Department of Pediatric Cardiovascular Surgery, Children's Medical Center, and ${ }^{\mathrm{b}}$ Division of Cardiovascular Surgery, Kyoto Prefectural University of Medicine, Kyoto, Japan.

Read at the 101st Annual Meeting of The American Association for Thoracic Surgery: A Virtual Learning Experience, April 30-May 2, 2021.

Received for publication May 1, 2021; accepted for publication Sept 3, 2021; available ahead of print Jan 21, 2022.

Address for reprints:Masaaki Yamagishi, MD, PhD, Department of Pediatric Cardiovascular Surgery, Children's Medical Center, Kyoto Prefectural University of Medicine, 465 Kajii-cho, Kamigyo-ku, Kyoto 602-8566, Japan (E-mail: myama@ koto. kpu-m.ac.jp).

2666-2507

Copyright (C) 2022 The Author(s). Published by Elsevier Inc. on behalf of The American Association for Thoracic Surgery. This is an open access article under the CC BY license (http://creativecommons.org/licenses/by/4.0/).

https://doi.org/10.1016/j.xjtc.2021.09.058
- Video clip is available online.

To view the AATS Annual Meeting Webcast, see the URL next to the webcast thumbnail.

Autologous pericardium is a material conventionally used in pediatric cardiovascular surgeries, especially for pulmonary artery (PA) surgical dilation and/or valve leaflet augmentation. As opposed to other materials such as artificial grafts, homografts, and xenografts, autologous 


\section{Abbreviations and Acronyms \\ AVP = aortic valve plasty \\ PA = pulmonary artery \\ RVOT $=$ right ventricular outflow tract \\ $\mathrm{TEVG}=$ tissue-engineered vascular graft}

pericardium is resistant to infection and calcification, does not provoke autoimmune responses, and has growth potential. However, the utility of autologous pericardium is limited because of various reasons, including adhesion effects after multiple thoracotomy or mediastinum inflammation and exhaustion in previous surgeries. ${ }^{1}$ Since 2014, we have been developing tissue-engineered vascular grafts (TEVGs) as alternatives to autologous pericardium for use in congenital heart surgeries, and have reported good results for the same. ${ }^{2-4}$ In this study we aimed to investigate the midterm outcomes of PA reconstruction and aortic valve plasty (AVP) with TEVGs.

\section{METHODS}

This study was approved by the institutional review board of the Kyoto Prefectural University of Medicine (approval number: ERB-C-162; approval date: May 12, 2014). Written informed consent was obtained from the patients' parents or guardians for the publication of their data.

\section{Methods}

TEVG molds were made from 19-French silicone drain tubes in a manner that ensured that there were no lumina in the molds (Figure 1, $A$ ). The molds were subsequently embedded in the upper abdominal subcutaneous space (Figure 1, $B$ ) either independently before the surgery or in a concomitant procedure at the time of previous surgeries. In each patient, we were able to insert the mold through a small skin incision that was a few centimeters wide. After more than 4 months after the implantation, the TEVGs were harvested intraoperatively (Video 1) and treated with $70 \%$ ethanol for 10 to 15 minutes while observing the TEVG strength; during harvesting, a skin incision was made directly above the mold to avoid damage to the TEVGs. The treated TEVGs were then used as patch materials by cutting them open (Figure 1, C).

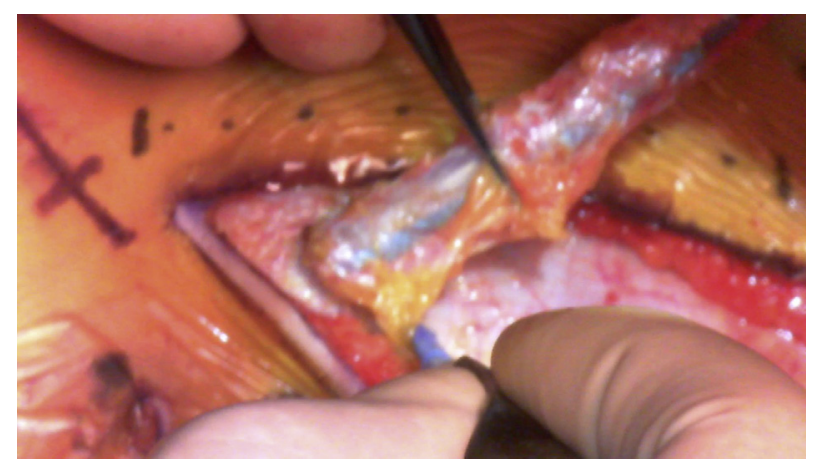

VIDEO 1. Harvest of tissue-engineered vascular graft mold. Video available at: https://www.jtcvs.org/article/S2666-2507(22)00016-5/fulltext.

\section{Data Collection and Analysis}

Clinical data were obtained from a retrospective review of medical records and operative and echocardiographic reports. Frequencies are presented as absolute numbers and percentages. Continuous data are presented as medians with ranges or as means with SDs.

\section{Patients}

Since July 2014, 6 patients and 1 patient have undergone PA reconstruction (Video 2) and AVP (Video 3) with TEVGs at our center, respectively (Figure 2; Tables E1, and E2). The diagnoses comprised pulmonary atresia, ventricular septal defect, and major aortopulmonary collateral arteries in 4 patients (group A); double-outlet right ventricle and coarctation of the aorta in 2 patients (group B); and transposition of the great arteries, ventricular septal defect, and left ventricular outflow tract obstruction in 1 patient (the AVP patient, group C). The median time from mold implantation to operation was 8.9 (range, 6.0-26.4) months. The median age and body weight of the patients at the time of the operation were 2.7 (range, 1.89.2) years and 11.6 (range, 7.9-24.4) kg, respectively. In group A, TEVG was embedded in 3 patients during the first palliative surgery (unifocalization with palliative right ventricular outflow tract [RVOT] reconstruction). Of these patients, 2 received TEVG for PA augmentation during the next Rastelli operation, whereas 1 did not meet the criteria for the Rastelli operation because of a hypoplastic PA. Consequently, this patient underwent repeat palliative PA augmentation with TEVG as the second palliative surgery and was awaiting a Rastelli operation at the time of this study. This patient was referred to our institution with the unifocalization and palliative RVOT reconstruction already performed in a previous institution. His PA

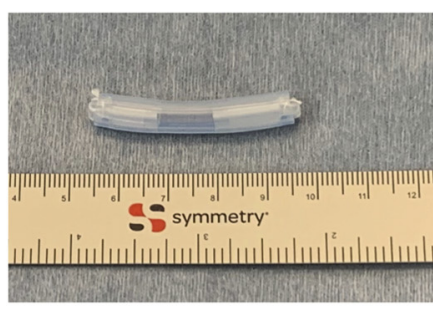

A
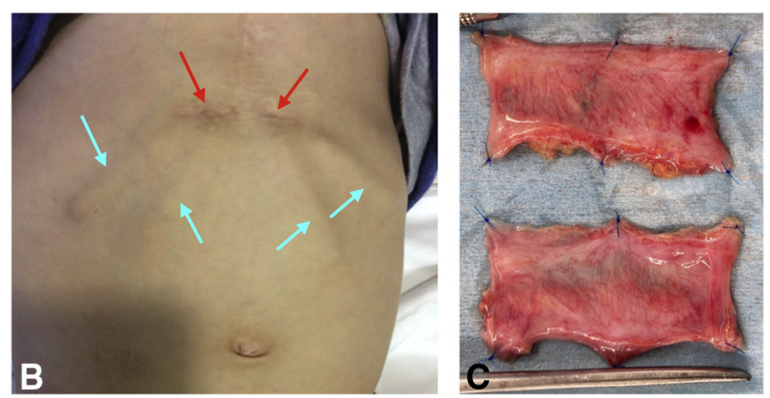

FIGURE 1. Images of the tissue-engineered vascular graft. A, A tissue-engineered vascular graft mold made with a 19-French silicone drain tube. B, Postoperative image of the local skin incision (red arrows) and 4 molds implanted in the subcutaneous spaces (blue arrows). C, Opened tissue-engineered vascular grafts. 


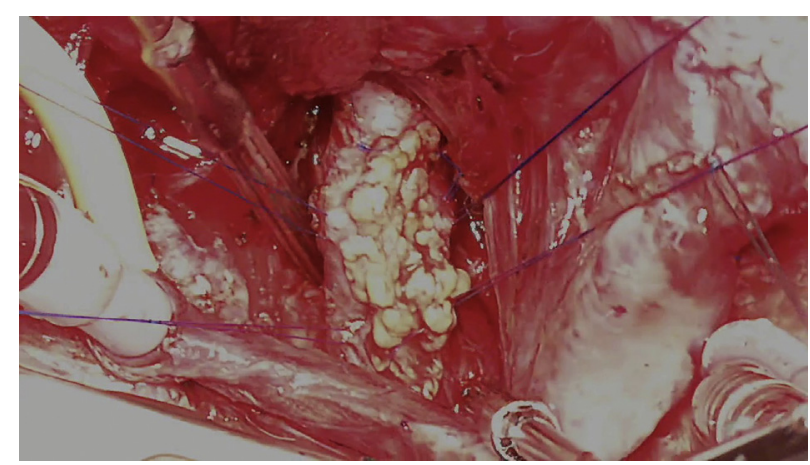

VIDEO 2. Pulmonary artery augmentation using tissue-engineered vascular graft. Video available at: https://www.jtcvs.org/article/S26662507(22)00016-5/fulltext.

was found to have multiple stenotic regions, especially in the right area. Therefore, we first performed PA augmentation using autologous pericardium and TEVG mold implantation. However, bronchus compressioninduced postoperative PA re-stenosis was observed (Figure 3, A). Two years after the previous operation, right PA augmentation with TEVG was performed.

In group B, both patients were univentricular candidates because of their complex intracardiac morphology. One patient underwent PA augmentation in a Fontan operation, and another underwent palliative RVOT reconstruction and was awaiting the next palliative surgery at the time of this study.

In group $\mathrm{C}$, a half-turned truncal switch operation ${ }^{5}$ was performed when the patient was 3 months old. The postoperative course was good; however, leaflet shortening-induced aortic regurgitation gradually worsened over the course of 8 years. Therefore, AVP was performed with TEVG at 9 years of age, approximately 1 year after TEVG mold implantation.

Anticoagulant therapy generally consisted of $2 \mathrm{mg} / \mathrm{kg}$ of acetylsalicylic acid. Moreover, warfarin was prescribed at least 6 months postoperatively, because we did not have any data on the patients' anticoagulant usage status after TEVG implantation.

\section{RESULTS}

The median follow-up period was 14.4 (range, 3-39.6) months. There were no early or late mortalities. In group A, the postoperative PA configuration was satisfactorily dilated in 3 patients, as shown in 3-dimensional cardiac computed tomography (Figure 4). In the patient who underwent right PA augmentation due to bronchus compression-induced PA re-stenosis (Figure 3, A), repeated PA augmentation with TEVG and mold implantation were performed and a good PA configuration was obtained (Figure 3, B). Finally, he underwent the Rastelli operation, and PA augmentation with TEVG was performed intraoperatively in a manner similar to that in the previous operation (Figure 3,C and $D$ ). In group B, both patients had a good postoperative PA configuration and no pulmonary hypertension. In all 6 cases with PA augmentation, postoperative hemorrhage from TEVG, aneurysmal change, infection, and thrombosis were not observed. The systolic PA pressures before and after TEVG implantation for each patient in group $\mathrm{A}$ are

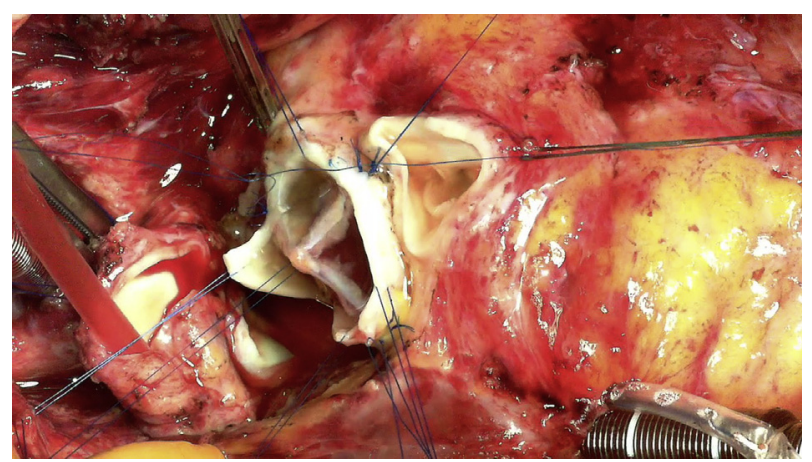

VIDEO 3. Aortic valvuloplasty using tissue-engineered vascular graft. Video available at: https://www.jtcvs.org/article/S2666-2507(22)00016-5/ fulltext.

shown in Table 1. In group $\mathrm{C}$, the function of the reconstructed aortic valve was good; only trivial to mild regurgitation and tiny stenoses were found in the neoaortic valve, and decreased leaflet flexibility due to leaflet thickening was not observed (Figure 5).

On pathological examination, the TEVGs had smooth luminal surfaces. The TEVG wall mainly consisted of collagen fibers and a few fibroblasts; however, elastic fiber formation and/or smooth muscle cells were not observed (Figure 6).

\section{DISCUSSION}

The study is summarized in Figure 7. In cardiovascular surgery, tissue engineering has attracted increasing attention in the past few decades. Some recent studies have indicated that it is possible to provide a TEVG that will remain patent in vivo for substantial use. Such TEVGs have been developed in vitro and are made of materials such as collagen gel, ${ }^{6}$ biodegradable scaffolds within dynamic bioreactors, ${ }^{7}$ nondegradable polyurethane scaffolds, ${ }^{8}$ and so on. However, in pediatric patients, we must consider the growth-associated size mismatch that occurs between TEVGs and the native vessels. Therefore, in this study, we focused on the clinical application of perfectly autologous TEVGs. Our TEVGs have autologous vascular prostheses that are on the basis of the tissueencapsulation phenomenon of foreign materials in living bodies, which is considered as a biological defense mechanism. ${ }^{9,10}$

Because the follow-up period in this study was short, we could not reach a consensus on whether TEVGs have a growth potential. However, in our longest-term follow-up experience of 3.3 years, no complications (such as aneurysmal dilatation or re-stenosis due to TEVG degeneration) were noted. Only 1 patient had PA re-stenosis after TEVG implantation; however, this was thought to be due to right bronchus posterior compression and was confirmed to not 


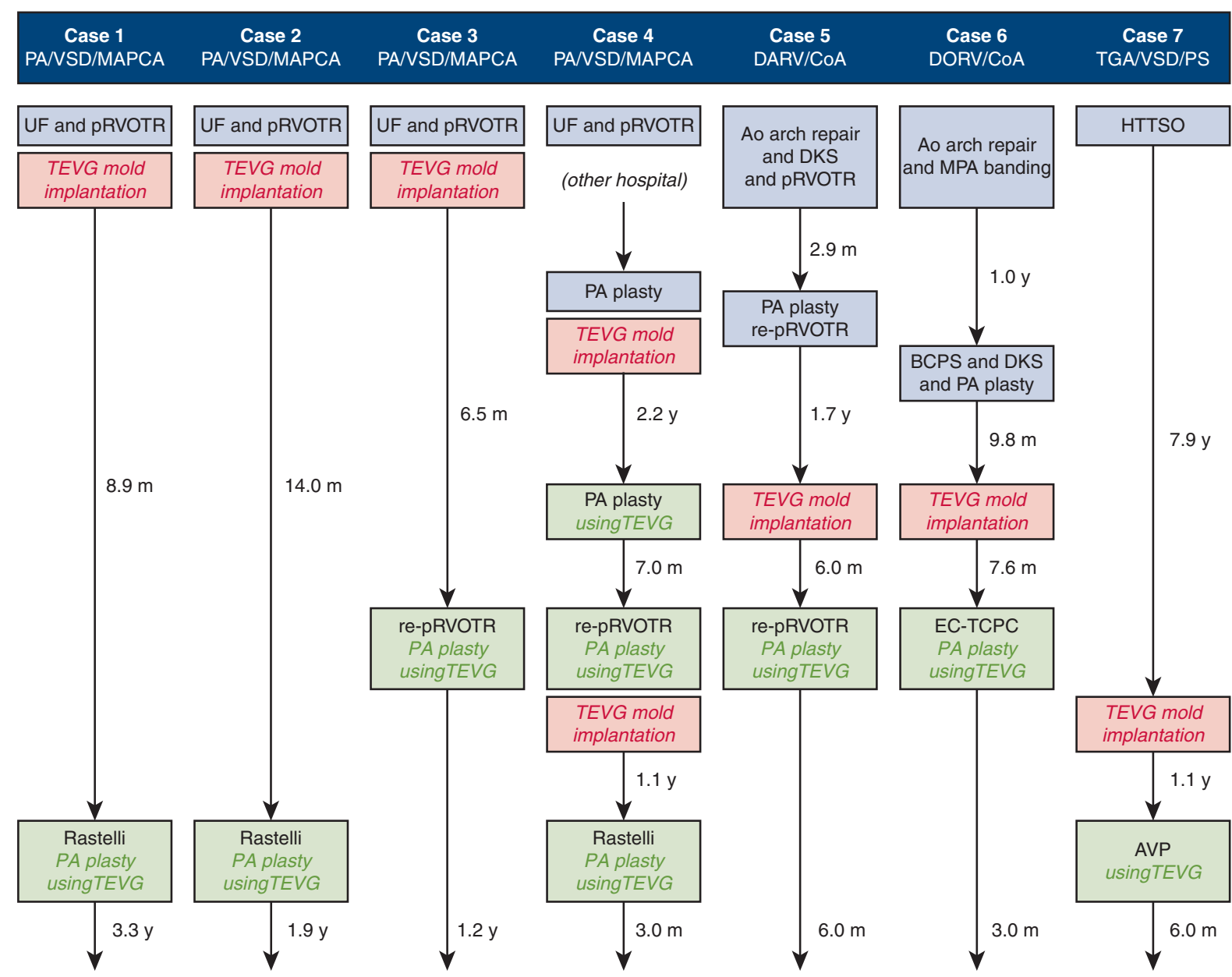

FIGURE 2. The profile of all 7 patients. $P A$, Pulmonary atresia; VSD, ventricular septal defect; MAPCA, major aortopulmonary collateral arteries; $D O R V /$ $C o A$, double-outlet right ventricle/coarctation of the aorta; TGA, transposition of the great arteries; $P S$, pulmonary stenosis; $U F$, unifocalization; $p R V O T R$, palliative right ventricular outflow tract reconstruction; $D K S$, Damus-Kaye-Stansel anastomosis; MPA, main pulmonary artery; HTTSO, half-turned truncal switch operation; TEVG, tissue-engineered vascular graft; $P A$, pulmonary artery; $B C P S$, bidirectional cavopulmonary connection; $E C$ - $T C P C$, extracardiac total cavopulmonary connection; $A V P$, aortic valve plasty.

have been caused by TEVG degeneration itself during the subsequent operation. Moreover, TEVG infection was not observed in any patient, which proved our hypothesis that TEVG is resistant to infection because it is composed of autologous tissue.

Furthermore, regarding the strength of TEVGs, Fujita and colleagues ${ }^{4}$ reported the mechanical strength of TEVGs. As for the suture retention strength, it was concluded that TEVG, the internal mammary artery, and the saphenous vein almost had the same strength. ${ }^{11,12}$ Additionally, Inoue and colleagues ${ }^{13}$ reported that a short duration of ethanol dehydration and glutaraldehyde treatment for crosslinking might improve surgical handling and burst pressure tolerance and successfully modify the mechanical properties of the aforementioned arteries without interfering with tissue regeneration. As for toxicity, glutaraldehyde is difficult to completely rinse off compared with ethanol, ${ }^{14}$ and clinical reports have mentioned that glutaraldehyde toxicity continues for a longer period in clinical settings. ${ }^{15,16}$ Considering the occurrence of calcification after glutaraldehyde treatment, ${ }^{16}$ our first choice is currently ethanol treatment.

The wall thickness differs between grafts harvested from humans and from other animals. For instance, the wall thickness of our TEVG was approximately $200 \mu \mathrm{m}$, whereas that of grafts harvested from rabbits and rats was $76 \mu \mathrm{m}$ and $56 \mu \mathrm{m}$, respectively. Therefore, our TEVGs were more than twice as thick as the other animal 

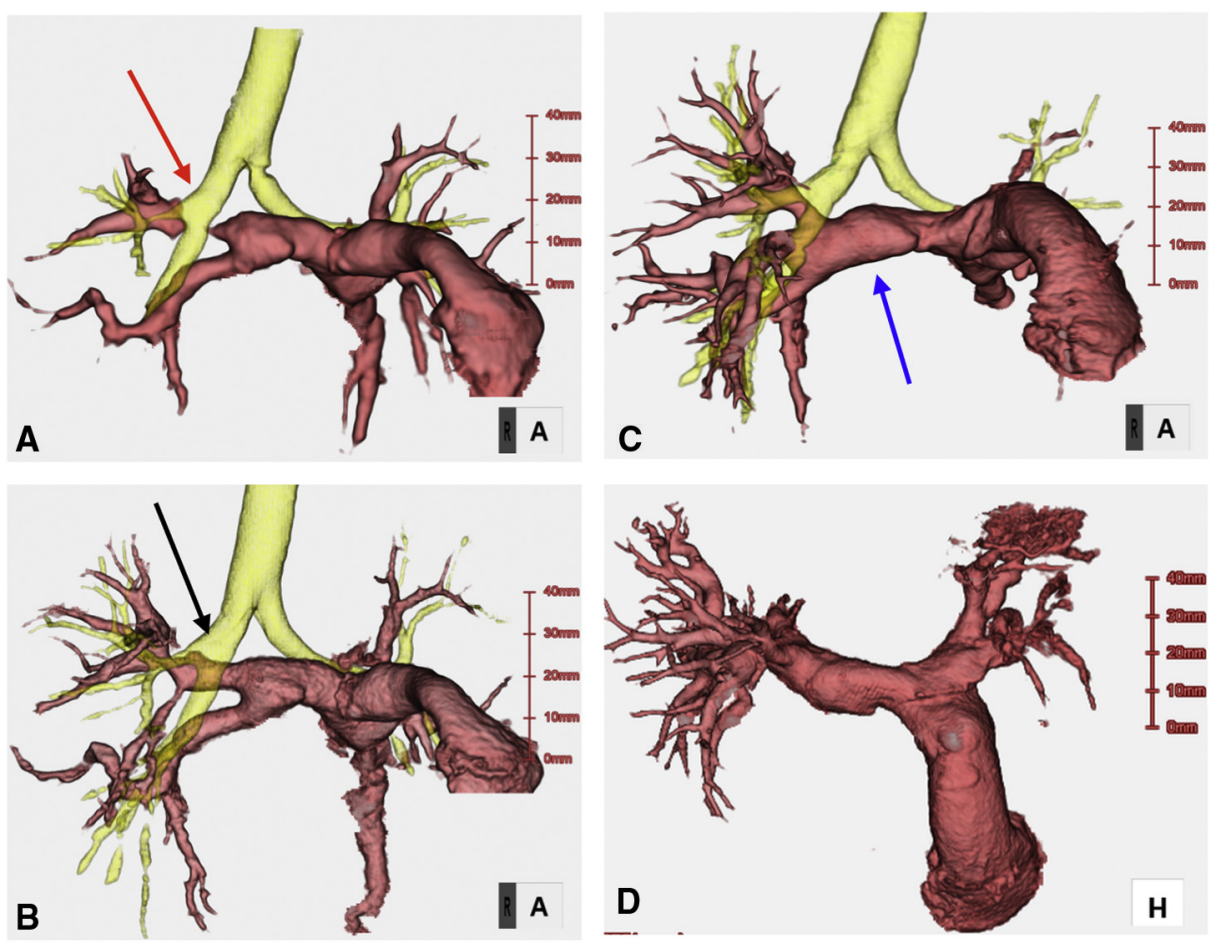

FIGURE 3. Pre- and postoperative 3-dimensional cardiac computed tomography scan of patient 4. A, Image taken after the first pulmonary artery augmentation with autologous pericardium. The distal right pulmonary artery is compressed by the right bronchus (red arrow). B, Image taken after pulmonary artery augmentation with tissue-engineered vascular graft patch for the first time. This patch was implanted at the stenotic region of the pulmonary artery (black arrow). C and D, Images taken after the final Rastelli operation. In the Rastelli operation, the graft was used again for the pulmonary artery (blue arrow).

grafts. ${ }^{2,3,17}$ In this study, we implanted the silicon mold subcutaneously for 6 months to 2 years; however, no associations were noted between the duration of mold implantation and the TEVG wall thickness. Therefore, we believe that the optimal incubation time in the body is at least 4 months.

As for the number of molds to be implanted, because these molds are harvested intraoperatively for use, they

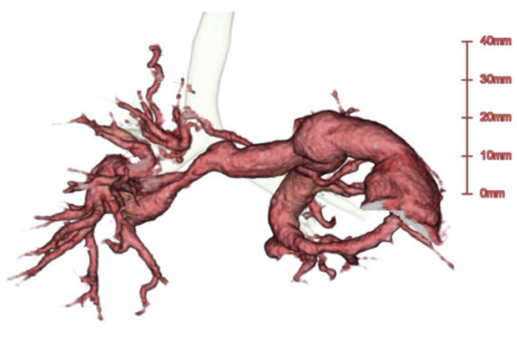

A

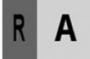

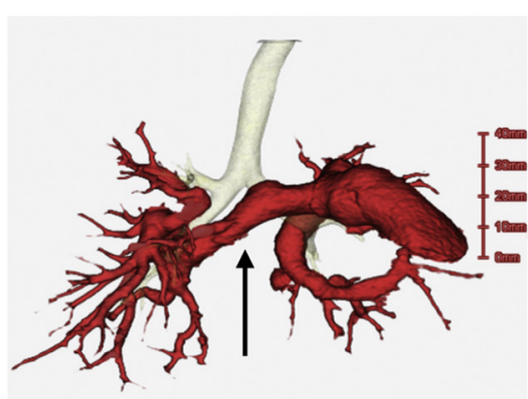

B

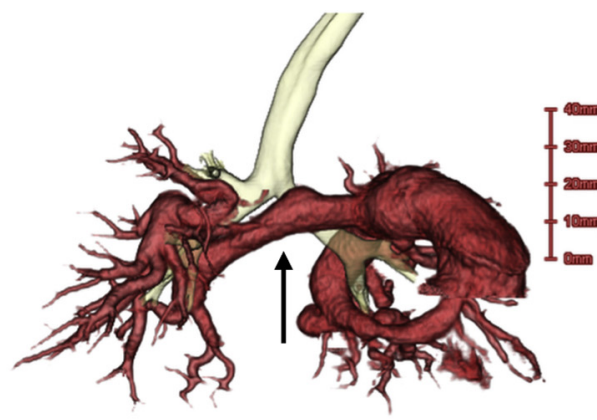

C

FIGURE 4. Pre- and postoperative 3 -dimensional cardiac computed tomography scan of patient 1. A, Preoperative image. B, Image taken a week after the operation. C, Image taken 40 months postoperatively. Tissue-engineered vascular graft was implanted at the stenotic region of the pulmonary artery (black arrow). 
TABLE 1. Transition of systolic pulmonary arterial pressure in each patient in group A

\begin{tabular}{|c|c|c|c|c|c|c|c|}
\hline Patient & $\begin{array}{l}\text { Preoperative } \\
\text { PAP, mm Hg }\end{array}$ & Second operation & $\begin{array}{l}\text { Postoperative } \\
\text { PAP, mm Hg }\end{array}$ & Third operation & $\begin{array}{l}\text { Postoperative } \\
\text { PAP, mm Hg }\end{array}$ & Fourth operation & $\begin{array}{l}\text { Postoperative } \\
\text { PAP, mm Hg }\end{array}$ \\
\hline 1 & 52 & $\begin{array}{l}\text { PA plasty with TEVG } \\
\text { Rastelli }\end{array}$ & 37 & - & - & - & - \\
\hline 2 & 30 & $\begin{array}{l}\text { PA plasty with TEVG } \\
\text { Rastelli }\end{array}$ & 46 & - & - & - & - \\
\hline 3 & 77 & $\begin{array}{l}\text { PA plasty with TEVG } \\
\text { Palliative Rastelli }\end{array}$ & 58 & - & - & - & - \\
\hline 4 & 70 & PA plasty with TEVG & 65 & $\begin{array}{l}\text { PA plasty with TEVG } \\
\text { Palliative Rastelli }\end{array}$ & 50 & $\begin{array}{c}\text { PA plasty with TEVG } \\
\text { Rastelli }\end{array}$ & $49^{*}$ \\
\hline
\end{tabular}

$P A P$, Pulmonary arterial pressure; $P A$, pulmonary artery; $T E V G$, tissue-engineered vascular graft. *For patient 4 , the PAP estimated from cardiac echography was used instead, because catheterization after the Rastelli operation had not yet been performed.

are implanted in the upper abdominal space; therefore, in our experience, a maximum of four 3- to 5-cm molds should be allowed in infants. However, we considered that TEVGs could be implanted not only in the upper abdominal space, but also in any subcutaneous space; therefore, it is possible that more TEVGs can be harvested as long as molds can be embedded. Moreover, as for the diameter of the molds to be embedded, a 19-French silicone tube, which is currently used as a drain tube in clinical settings, is generally used because of the risk of skin ulcer formation secondary to pressure on the dermis from the embedding of an excessively thick mold.
In an in vitro study performed by our team, vascular grafts showed tissue regeneration, including complete endothelialization 2 years after implantation. ${ }^{2}$ In vivo, we did not harvest the implanted TEVG patch at reoperation; therefore, we have no histological data on the implanted TEVG patch in clinical settings. Further investigations are thus required.

\section{Limitation}

This was a single-center, retrospective study. Moreover, this study was not comparative; therefore, the superiority of TEVG over other materials, including autologous pericardium, may not be evaluated.
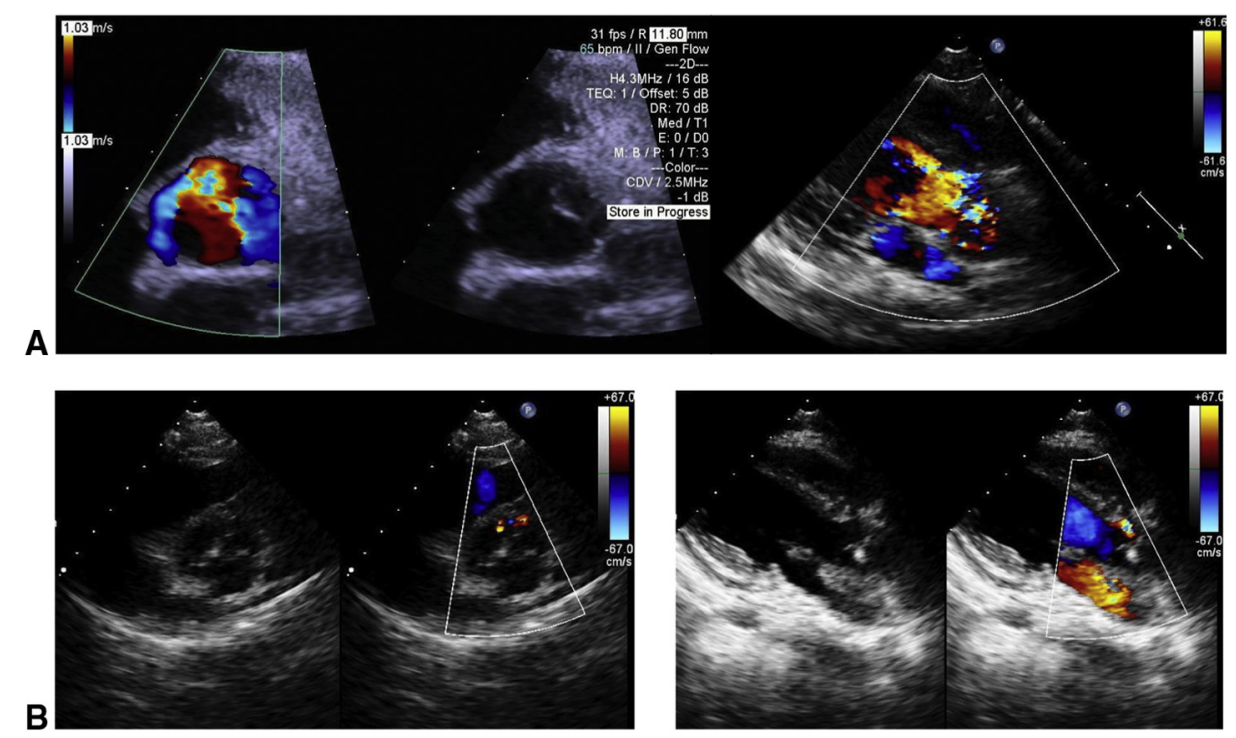

FIGURE 5. Pre- and postoperative cardiac echography image of patient 7. A, Preoperative image. Moderate to severe aortic regurgitation due to valve leaflet shortening was observed. B, Image taken approximately 3 months postoperatively. Aortic regurgitation improved to trivial to mild regurgitation. 

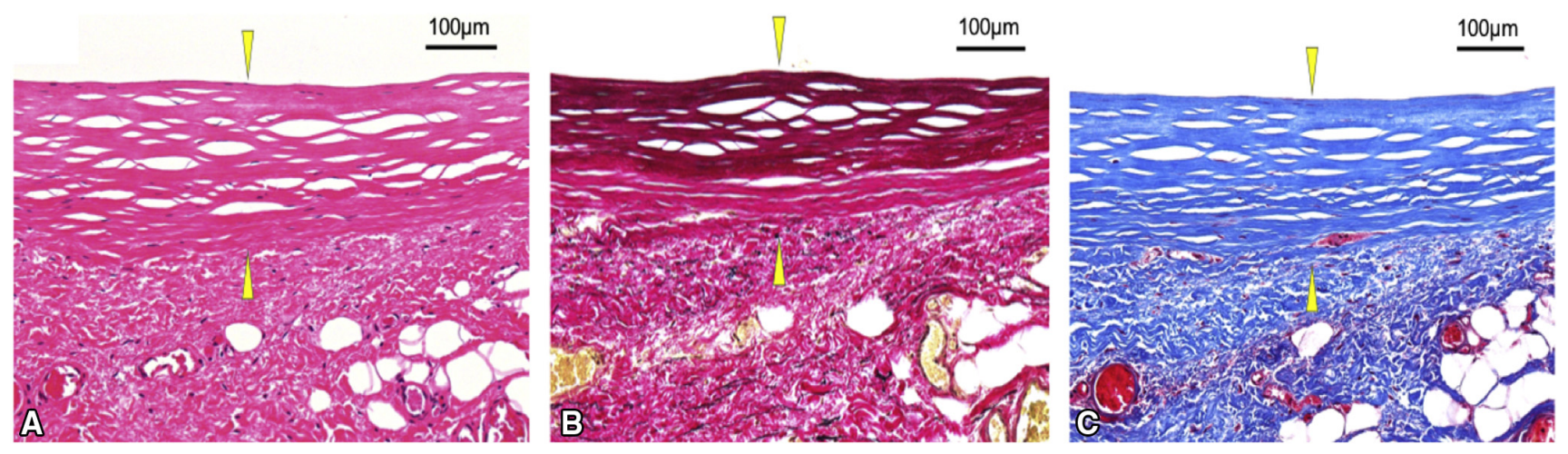

FIGURE 6. The cross-section was stained with hematoxylin and eosin (A), Masson trichrome (B), and Elastica Van Gieson (C). The yellow arrow heads define the depth of the graft walls. The Masson trichrome stain shows that the wall comprises collagen-rich tissue. Elastica Van Gieson staining shows the absence of elastic fiber networks.

\section{CONCLUSIONS}

The results of PA reconstruction and AVP with TEVG were satisfactory. TEVG-related complications, including aneurysmal change, infection, degeneration resulting in re-stenosis, and hemorrhage, were not observed. Although further follow-up will be needed, our study has revealed that TEVGs are useful alternatives to autologous pericardium in pediatric cardiovascular surgeries that often require multistage operations.

\section{Webcast}

You can watch a Webcast of this AATS meeting presentation by going to: https://aats.blob.core.windows.net/media/21\% 20AM/AM21_C11/AM21_C11_07_updated.m4v.

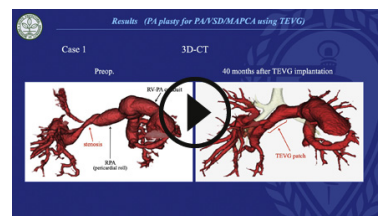

Pulmonary artery augmentation and aortic valve repair using the tissue-engineered graft

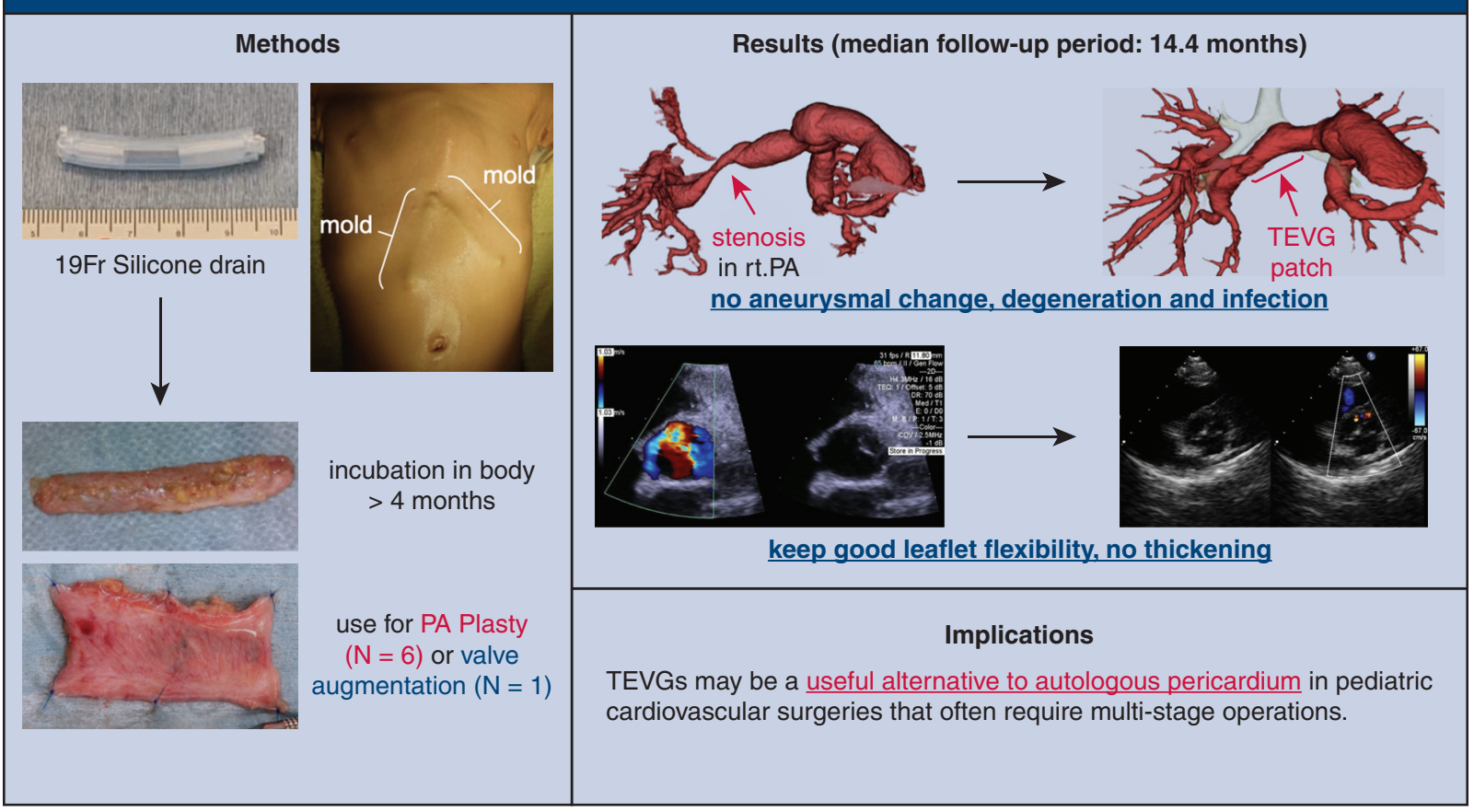

FIGURE 7. Graphical abstract of this report. $19 F, 19$-French; $r t$., right; $P A$, pulmonary artery; TEVG, tissue-engineered vascular graft. 


\section{Conflict of Interest Statement}

The authors reported no conflicts of interest.

The Journal policy requires editors and reviewers to disclose conflicts of interest and to decline handling or reviewing manuscripts for which they may have a conflict of interest. The editors and reviewers of this article have no conflicts of interest.

\section{References}

1. Venuta F, Ciccone AM. Reconstruction of the pulmonary artery. Semin Thorac Cardiovasc Surg. 2006;18:104-8.

2. Watanabe T, Kanda K, Yamanami M, Ishibashi-Ueda H, Yaku H, Nakayama Y. Long-term animal implantation study of biotube-autologous small-caliber vascular graft fabricated by in-body tissue architecture. J Biomed Mater Res B Appl Biomater. 2011;98:120-6.

3. Watanabe T, Kanda K, Ishibashi-Ueda H, Yaku H, Nakayama Y. Autologous small-caliber "biotube" vascular grafts with argatroban loading: a histomorphological examination after implantation to rabbits. J Biomed Mater Res B Appl Biomater. 2010;92:236-42.

4. Fujita S, Yamagishi M, Kanda K, Maeda Y, Inoue T, Yamanami M, et al. Histology and mechanics of in vivo tissue-engineered vascular graft for children. Ann Thorac Surg. 2020;110:1050-4.

5. Yamagishi M, Shuntoh K, Matsushita T, Fujiwara K, Shinkawa T, Miyazaki T, et al. Half-turned truncal switch operation for complete transposition of the great arteries with ventricular septal defect and pulmonary stenosis. J Thorac Cardiovasc Surg. 2003;125:966-8.

6. Copes F, Pien N, Van Vlierberghe S, Boccafoschi F, Mantovani D. Collagenbased tissue engineering strategies for vascular medicine. Front Bioeng Biotechnol. 2019;7:166.

7. Melchiorri AJ, Bracaglia LG, Kimerer LK, Hibino N, Fisher JP. In vitro endothelialization of biodegradable vascular grafts via endothelial progenitor cell seeding and maturation in a tubular perfusion system bioreactor. Tissue Eng Part C Methods. 2016;22:663-70.

8. Ratcliffe A. Tissue engineering of vascular grafts. Matrix Biol. 2000;19: 353-7.

9. Sparks CH. Autogenous grafts made to order. Ann Thorac Surg. 1969;8: 104-13.

10. Nakayama Y, Ishibashi-Ueda H, Takamizawa K. In vivo tissue-engineered smallcaliber arterial graft prosthesis consisting of autologous tissue (biotube). Cell Transplant. 2004;13:439-49.

11. L'heureux N, Dusserre N, Konig G, Victor B, Keire P, Wight TN, et al. Human tissue-engineered blood vessels for adult arterial revascularization. Nat Med. 2006; 12:361-5.

12. Konig G, McAllister TN, Dusserre N, Garrido SA, Iyican C, Marini A, et al. Mechanical properties of completely autologous human tissue engineered blood vessels compared to human saphenous vein and mammary artery. Biomaterials. 2009;30:1542-50.

13. Inoue T, Kanda K, Yamanami M, Kami D, Gojo S, Yaku H. Modifications of the mechanical properties of in vivo tissue-engineered vascular grafts by chemical treatments for a short duration. PLoS One. 2021;16:e248346.

14. Neethling WM, Glancy R, Hodge AJ. Mitigation of calcification and cytotoxicity of a glutaraldehyde-preserved bovine pericardial matrix: improved biocompatibility after extended implantation in the subcutaneous rat model. J Heart Valve Dis. 2010;19:778-85.

15. Luk A, David TE, Butany J. Complications of Bioglue postsurgery for aortic dissections and aortic valve replacement. J Clin Pathol. 2012;65:1008-12.

16. Jorge-Herrero E, Garcia Paez JM, Del Castillo-Olivares Ramos JL. Tissue heart valve mineralization: review of calcification mechanisms and strategies for prevention. J Appl Biomater Biomech. 2005;3:67-82.

17. Yamanami M, Ishibashi-Ueda H, Yamamoto A, Iida H, Watanabe T, Kanda K, et al. Implantation study of small-caliber "biotube" vascular grafts in a rat model. J Artif Organs. 2013;16:59-65.

Key Words: tissue-engineered vascular grafts, autologous pericardium, pulmonary artery, aortic valve plasty, pediatric cardiovascular surgery

\section{Discussion}

\section{Presenter: Dr Hisayuki Hongu}

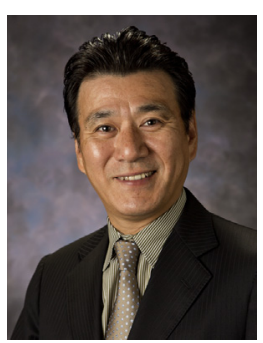

Dr Toshiharu Shinoka (Columbus, Ohio). I would like to thank the AATS, Dr Brown, and Dr Romano for the opportunity to discuss this report today. Congratulations to Dr Hongu, Dr Yamagishi, and colleagues for your exciting and unique preclinical procedural techniques. I would also like to thank Dr Hongu for providing me with your manuscript well in advance. I have several questions.

The idea to create autoregressive vascular graft in vivo by subcutaneously implanting a silicone manual was originally reported by Dr Sparks in 1969. They used Dacron reinforced grafts for the replacement of pulmonary arteries. This concept was abandoned soon because of the high incidence of infection, low patency, and aneurysmal formation?

I also have experience with dermal in vivo tissue engineering for the abnormal aorta replacement by using the same method as your method, in a sheep model in 1995. We used a fresh graft without any fixation. Unfortunately, our sheep died within 48 hours, because of the graft rupture. Your external fixation would be a great idea to strengthen the materials.

Dr Hongu, do you believe these dermal tissue constructs would be able to tolerate a systemic blood pressure? If the PA pressure is high, what would be the pressure limit that this growth can tolerate? How do you consider that this material could be used in aortic arch repair? And you have various periods of mold implantation from 6 months to 2 years, what do you think is the optimal duration for this graft to incubate in the body? Do you think a longer incubation period is better to create stronger tissue?

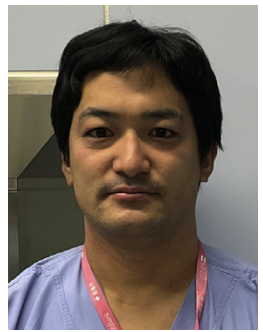

Dr Hongu (Kyoto, Japan). Thank you Professor Shinoka. I'm really grateful for the opportunity to present in such a honored meeting and would like to thank Dr Brown and Dr Romano very much.

I will answer from the first question. In our research, of course, the detailed in vivo data whether the TEVG can withstand the arterial pressure was not obtained. However, the result of mechanical property tests showed that the clinically harvested TEVG fragments were stronger than IMA with ethanol treatment, indicating that they may be used as an arterial graft.

So, theoretically, TEVG can be tolerated for any pulmonary hypertension.

In our clinical case, TEVG could be safely used for moderate pulmonary hypertension cases. The patient's pulmonary artery pressure was approximately $70 \%$ of arterial 
pressure due to hypoplastic MAPCA. But TEVG did not show any aneurysmal change in a 1.2-year follow-up.

In our test, glutaraldehyde fixation showed almost the same, or very slightly stronger than ethanol treatment. So, take into consideration the toxicity and the calcification, we apply the ethanol treatment.

In an in vitro trial, TEVG can be made at least 4 weeks in the animal body. However, to use in vivo, we have longer incubation period for safety margin. In addition, the degree of the TEVG was not associated with the incubation period.

Dr Shinoka. Thank you. My next question is related to the application to the valve leaflet. In 1995, when I was working as a research fellow in at Boston Children's Hospital, we tried to create a tissue-engineered pulmonary valve leaflet in a sheep model. I compared dermal fibroblast seeded leaflet with the vascular cell seeded valve leaflet in the pulmonary valve position in a sheep model. Unfortunately, all of the dermal valve leaflets shrunk down within 6 months while the vascular cell tissue engineered showed better performance. Could you describe in more detail about the long-term results of your prepared valve?

Dr Hongu. Thank you for your question. We used TEVG for valve leaflet extension. Because we had no experience with using TEVG for valvuloplasty, we did not resect the leaflet and replace it with TEVG, but only for shortening the valve leaflet extension. Furthermore, because we have experience of valve replacement with autologous pericardium in cases such as truncus arteriosus, we planned to use autologous pericardium as the first option in this case as well. However, in the case of re-sternotomy, as expected, it was not possible to extend all 3 leaflets with only the autologous pericardium, which led to the use of TEVG for the right coronary cusp. The follow-up period of this case was only 6 months. So careful follow-up is needed, especially for the right coronary cusp using TEVG.

Dr Shinoka. My final question is regarding the histological results that you show in your manuscript. We reported a long-term histological result of autologous pericardium implanted in the pulmonary artery position in 2 patients. This report was published in the New England Journal of Medicine in 2003. Both patients had redo surgery after PA angioplasty and we had the opportunity to harvest the previously implanted pericardium tissue. The histology in both patients showed a well remodeled pulmonary artery structure, including an abundance of the smooth muscle cell layer reuse and a single layer of endothelial cells after the 3 years post implementation.

We concluded that autologous fresh pericardium is a good scaffold material to create a tissue-engineered pulmonary artery in vivo in some patients. Your longest follow-up is 3 years in this series. I am wondering why your graft histology had no smooth muscle cells. Did you see any endothelial cells on the surface of the graft? Or do you have any large animal data that supports later smooth muscle cell migration on your graft?

Dr Hongu. Thank you for your question. Because the histological image shown in this presentation is the image before implantation, we don't have accurate evidence of histological data after implantation. Before implantation, it consists of collagen fibers and fibroblasts, which are common to small animals, large animals, and humans.

In small and large animals, endothelium of the lumen surface and formation of the vascular media layer by smooth muscle cells have been observed several months after implantation in blood vessels. The TEVG histology of the aorta has not been published. Also, examination of tissue histological change after implantation in humans is a future theme. We have some experiences of autologous pericardium implantation for pulmonary coarctation, and the histological examination showed complete endothelialization, tiny smooth muscle cells, and a rich collagen fiber layer.

I have no idea why our harvested tissue was different from your study. Sorry.

Dr Shinoka. Okay. Congratulations again, to Dr Hongu and Dr Yamagishi for your brave clinical challenge. 
TABLE E1. Demographic characteristics patients in group A

\begin{tabular}{|c|c|c|c|c|}
\hline & \multicolumn{4}{|c|}{ Patient number (group A) } \\
\hline & 1 & 2 & $\mathbf{3}$ & 4 \\
\hline Diagnosis & \multicolumn{4}{|l|}{ PA/VSD/MAPCA } \\
\hline First operation (our institution) & \multicolumn{3}{|c|}{ UF/pRVOTR, TEVG mold implantation } & PA plasty, TEVG mold implantation \\
\hline Age/BW at first operation & 2.0 Years $/ 10.0 \mathrm{~kg}$ & 1.3 Years $/ 7.3 \mathrm{~kg}$ & 1.3 Years $/ 7.3 \mathrm{~kg}$ & 4.8 Years $/ 15.4 \mathrm{~kg}$ \\
\hline Interval & 8.9 Months & 14.0 Months & 6.5 Months & 2.2 Years \\
\hline Second operation & $\begin{array}{l}\text { Rastelli } \\
\text { PA plasty with TEVC }\end{array}$ & & $\begin{array}{l}\text { re-pRVOTR } \\
\text { PA plasty with TEVG }\end{array}$ & PA plasty with TEVG \\
\hline Age/BW at second operation & 2.7 Years $/ 11.6 \mathrm{~kg}$ & 2.4 Years $/ 9.1 \mathrm{~kg}$ & 1.8 Years $/ 7.9 \mathrm{~kg}$ & 7.0 Years $/ 19.0 \mathrm{~kg}$ \\
\hline Interval & - & - & - & 7.0 Months \\
\hline Third operation & & & & $\begin{array}{l}\text { re-pRVOTR } \\
\text { PA plasty with TEVG } \\
\text { TEVG mold implantation }\end{array}$ \\
\hline Age/BW at third operation & & & & 7.8 Years $/ 19.6 \mathrm{~kg}$ \\
\hline Interval & & & & 1.1 Year \\
\hline Fourth operation & & & & $\begin{array}{l}\text { Rastelli } \\
\text { PA plasty with TEVG }\end{array}$ \\
\hline Age/BW at fourth operation & & & & 8.8 Years $/ 21.8 \mathrm{~kg}$ \\
\hline Follow-up from last operation & 3.3 Years & 1.9 Years & 1.2 Years & 3.0 Months \\
\hline
\end{tabular}

TABLE E2. Demographic characteristics of patients in groups B and C

\begin{tabular}{|c|c|c|c|}
\hline & \multicolumn{3}{|c|}{ Patient number (groups B and C) } \\
\hline & 5 & 6 & 7 \\
\hline Diagnosis & DORV/CoA & & TGA/VSD/PS \\
\hline First operation & Bilateral PA banding & & HTTSO \\
\hline Age/BW at first operation & 9 Days $/ 3.0 \mathrm{~kg}$ & 8 Days $/ 2.6 \mathrm{~kg}$ & 3.0 Months $/ 5.4 \mathrm{~kg}$ \\
\hline Interval & 8.9 Months & 2 Months & 7.9 Years \\
\hline Second operation & $\begin{array}{l}\text { Arch repair, DKS } \\
\text { pRVOTR }\end{array}$ & $\begin{array}{l}\text { Arch repair } \\
\text { MPA banding }\end{array}$ & TEVG mold implantation \\
\hline Age/BW at Second operation & 2.7 Months $/ 4.6 \mathrm{~kg}$ & 2.0 Months $/ 3.8 \mathrm{~kg}$ & 8.0 Years $/ 22.3 \mathrm{~kg}$ \\
\hline Interval & 2.9 Months & 1.0 Years & 1.1 Years \\
\hline Third operation & $\begin{array}{l}\text { PA plasty } \\
\text { re-pRVOTR }\end{array}$ & $\begin{array}{l}\text { BCPS, DKS } \\
\text { PA plasty }\end{array}$ & AVP with TEVG \\
\hline Age/BW at third operation & 5.1 Months/4.7 kg & 1.2 Years $/ 8.6 \mathrm{~kg}$ & 9.2 Years $/ 24.4 \mathrm{~kg}$ \\
\hline Interval & 1.7 Years & 9.8 Months & - \\
\hline Fourth operation & TEVG mold implantation & & - \\
\hline Interval & 6.0 Months & 7.6 Months & \\
\hline Fifth operation & $\begin{array}{l}\text { re-pRVOTR } \\
\text { PA plasty with TEVG }\end{array}$ & $\begin{array}{l}\text { EC-TCPC } \\
\text { PA plasty with TEVG }\end{array}$ & \\
\hline Follow-up from last operation & 6.0 Months & 3.0 Months & 6.0 Months \\
\hline
\end{tabular}

